\title{
Unresectable Pleural Malignant Mesothelioma
}

National Cancer Institute

\section{Source}

National Cancer Institute. Unresectable Pleural Malignant Mesothelioma. NCI Thesaurus.

Code C154444.

Malignant mesothelioma of the pleura that is not amenable to surgical resection. 